\title{
Oxalates are Found in Many Different European and Asian Foods - Effects of Cooking and Processing
}

\author{
Geoffrey Savage ${ }^{1} \&$ Warinporn Klunklin ${ }^{1}$ \\ ${ }^{1}$ Department of Wine, Food and Molecular Biosciences, Lincoln University, Canterbury, New Zealand \\ Correspondence: Geoffrey Savage, Department of Wine, Food and Molecular Biosciences, Lincoln University, \\ Canterbury, New Zealand. E-mail: savage@ lincoln.ac.nz
}

Received: March 9, 2018

Accepted: March 23, 2018 Online Published: April 6, 2018

doi:10.5539/jfr.v7n3p76

URL: https://doi.org/10.5539/jfr.v7n3p76

\begin{abstract}
Plant foods contain a surprising number of different toxins. A few well-known plants, including some grown in Thailand are known to contain high levels of oxalates however, some plants have not yet been fully investigated. A few plants have become fashionable to promote health because they contain antioxidants but some of these plants will contain oxalates as well. In many cases there is little published data to confirm the oxalates levels of these plants. If plant leaves are boiled before they are consumed this allows soluble oxalate to be leached out and discarded in the cooking water. This means that the cooked food contains considerably lower levels of soluble oxalates than the original raw plants. Cooking in a wok generally concentrates the oxalate contents as much of the cooking water is removed as steam. However, during cooking some of the soluble oxalates can combine with free calcium in the food and be converted to insoluble oxalates; these are not absorbed in the digestive tract. The preparation of juices using fruit or vegetables are being promoted as healthy alternatives, this poses further problems, as they may be prepared from raw vegetable leaves, such as spinach, which contain high levels of oxalates. These juices are not cooked so the oxalate concentration is not reduced during their preparation. Recent research has shown that the addition of calcium salts to these juices can considerably reduce the soluble oxalate content of the drink prepared without changing the taste.
\end{abstract}

Keywords: soluble and insoluble oxalates, boiling, wok-cooking

\section{Introduction}

Oxalates can be found in relatively small amounts in many plants. Oxalate-rich foods are usually minor components in human diets but are sometimes important in seasonal diets in certain areas of the world. Oxalic acid forms water-soluble salts with $\mathrm{Na}^{+}, \mathrm{K}^{+}$and $\mathrm{NH}_{4}{ }^{+}$ions, and also binds with $\mathrm{Ca}^{2+}, \mathrm{Fe}^{2+}$ and $\mathrm{Mg}^{2+}$, rendering these minerals unavailable (Noonan \& Savage, 1999). Food plants commonly contain both soluble and insoluble oxalates. There are different methods for determining soluble and insoluble oxalates (Noonan \& Savage, 1999), but the most reliable method uses simple hot water and acid extractions from foods followed by HPLC analysis (Savage et al., 2000). Total, soluble and insoluble oxalates are expressed in $\mathrm{mg} / 100 \mathrm{~g}$ of the plant material either on a wet matter (WM) or dry matter basis (DM). Soluble oxalates in food plants have two main effects: 1) they can bind in the gastrointestinal tract with soluble calcium in the food; or 2) they can bind with calcium in other foods eaten at the same time, but this makes the calcium unavailable. Soluble oxalates from foods that remain unbound are readily absorbed from the gastrointestinal tract but, as oxalates cannot be utilised in the body, they are quickly excreted by the kidneys. When oxalates are being excreted they can combine with calcium that is being excreted at the same time. This leads to the formation of kidney stones. Oxalate is also an end-product of metabolism in the liver some amino acids and carbohydrates are degraded to oxalate there (Hodgkinson, 1977; Noonan \& Savage, 1999). This means that the additional oxalate derived from food increases the total excretion of oxalate by the kidneys. The problem is the formation of oxalate-containing stones in the kidneys, which can, eventually, move down into the ureter. Kidney stones have a very rough crystalline structure so can cause considerable pain as they pass down the ureter. This pain usually motivates people to reduce the possibility of developing further kidney stones by decreasing their intake of high oxalate containing foods. However, the endogenous production of oxalates cannot be effectively reduced. It has been estimated that the median urinary oxalate excretion in men and women is approximately 39 and $27 \mathrm{mg} /$ day, respectively (Taylor \& Curhan, 2008).

Kidney stone disease is painful and can be life threatening. Statistics show that kidney stone disease occurs in 
many parts of the world and its incidence is rising. Recent data in the USA revealed that the lifetime kidney stone disease has increased, since 1994, from 6.3 to $10.5 \%$, in men and from 4.1 to $7.1 \%$, in women (Scalels et al., 2012). This study also indicated that kidney stone disease was more common in obese rather than normal weight persons. This emphasizes the impact of food and nutrition on the incidence of this disease. Another study in Pakistan showed that the highest prevalence of kidney stone disease in males and females was in the age groups of 40 - 49 and 30 - 39, respectively (Ahmed et al., 2016). This study also confirmed that the prevalence of this disease is higher in men than in women.

Dietary oxalates play a significant role in kidney stone formation. The importance of observing some food and dietary measures to lessen the probability of suffering from such a disease has been reviewed extensively by Massey (2003). Endogenous synthesis is proportional to body mass and cannot be reduced by any change in oxalate intake. Oxalates can be found in all plant foods; however, certain plants contain very high levels and people who are prone to kidney stone formation are advised not to eat these foods. There is a consensus by reputable authorities (National Kidney Foundation, 2014; Harvard Health Publications, 2017; Mayo Clinic (nd); National Institute of Diabetes and Digestive and Kidney Diseases, 2016) that several steps need to be followed to protect from, or lessen, the probability of kidney stones. These are: 1) moderating the intake of oxalate-rich foods; 2) drinking enough water to prevent the urine from being too concentrated; 3) reducing the animal protein intake; 4) increasing the calcium intake; 5) reducing the intake of sodium; and 6) drinking juices that contain citric acid. In addition, the cooking of potentially high oxalate containing foods needs to be considered. Boiling foods to allow the leaching of oxalates into the cooking water needs to be more widely practised. Frying foods in a wok needs further consideration as this process tends to concentrate oxalates in the cooked foods. The current trend of preparing fresh juices from raw vegetables and fruit (commonly called juicing) needs to be recognised as a potential way to consume very large amounts of soluble oxalates.

\subsection{Oxalate Content of European and Asian Plant Foods}

The oxalate contents of plant foods vary widely. There are several databases that record the oxalate contents of common foods (USDA, 1984). An early comprehensive summary of the oxalate contents of common vegetables (Noonan \& Savage, 1999) was supplemented with the sources and effects of oxalates in the body. The foods containing the highest total oxalate contents on a fresh weight (FW) basis from this study are summarised in Table 1. Later, Massey (2003) presented more data on some common oxalate containing foods, while Chai \& Lieberman (2005) presented data for a range of legumes, nuts and grain-based flours. Ruan et al., (2013) also presented an interesting summary of a wide range of foods commonly eaten in Southern China, while Judprasong et al., (2006) published a very comprehensive summary of foods commonly eaten in Thailand (Table 3). This was followed by a summary of a selected group of raw and cooked vegetables by Juajun et al., (2012) (Table 4). The studies of Ritter \& Savage (2007) presented data on a range of tree nuts and this list has been extended by data presented by the USDA (2016), while Charrier et al., (2000) presented data on a range of black and green teas, and Nguyen et.

Table 1. Total oxalate (mg/100 g FW) mean literature values summarised by Noonan \& Savage (1999)

\begin{tabular}{lll}
\hline Foodstuff & Range & Mean \\
\hline Rhubarb raw & $275-1336$ & 805 \\
Rhubarb boiled & 460 & - \\
Red beetroot & $121-450$ & 275 \\
Beetroot leaves & $300-920$ & 610 \\
Spinach leaves & $320-1260$ & 970 \\
Garden orach leaves & $300-1500$ & 900 \\
NZ spinach leaves & 890 & - \\
Cocoa & $500-900$ & 700 \\
Tea leaves & $300-2000$ & 1150 \\
Purslane leaves & $910-1679$ & 1294 \\
Parsley & $140-200$ & 170 \\
\hline
\end{tabular}


Table 2. Mean oxalate content of common raw and cooked New Zealand foods (mg/100 g FW) (Savage et al., 2000)

\begin{tabular}{lllllll}
\hline Foodstuff & \multicolumn{2}{l}{ Total oxalate } & \multicolumn{2}{l}{ Soluble oxalate } & \multicolumn{2}{l}{ Insoluble oxalate } \\
\hline & Raw & Cooked & Raw & Cooked & Raw & cooked \\
\hline Silver beet leaves & 525.5 & 291.1 & 252.3 & 117.7 & 273.2 & 173.4 \\
Silver beet stems & 127.4 & 148.4 & 24.0 & 19.4 & 103.4 & 129.0 \\
NZ Spinach & 1764.7 & 1322.6 & 364.6 & 129.3 & 1400.1 & 1193.3 \\
Spinach & 329.6 & 154.8 & 266.2 & 90.9 & 63.4 & 63.9 \\
Rhubarb & 986.7 & 756.3 & 287.3 & 80.7 & 699.4 & 675.6 \\
Beetroot & 45.6 & 76.0 & 38.6 & 72.3 & 7.0 & 3.7 \\
Broccoli & 16.1 & 10.1 & 11.6 & 6.6 & 4.5 & 3.5 \\
Carrot & 35.6 & 32.3 & 22.6 & 19.3 & 13.0 & 13.0 \\
Parsnip & 12.0 & 10.5 & 9.2 & 7.0 & 2.8 & 3.5 \\
\hline
\end{tabular}

al. (2018), on values for cocoa. Coffee, on the other hand, has been shown in more detailed studies to contain no oxalate (although it is sometimes reported to be present in very small amounts in minor studies). Radek \& Savage (2008) presented data on the oxalate contents of foods and spices from India. A comprehensive analysis of a wide range of locally grown and imported fruits has been presented by Nguyen \& Savage (2012, 2013).

A feature of the analyses carried out before 1999 was that most authors concentrated on the total oxalate contents of foods. An important feature of some later publications is the presentation of data on both the total, soluble and insoluble oxalate contents of foods. Many studies have shown that the insoluble oxalate fraction, which is mainly calcium oxalate, is not absorbed from the digestive tract so is not important for human nutrition. The most useful publications also present data on various foods after they have been cooked. These give more realistic values for the actual soluble oxalate ingested and potentially absorbed from the small intestine (see Table 2). This table highlights the large differences between the oxalate contents of the leaves and fleshy stems of silver beet (Note: silver beet is sometimes referred to as Swiss chard). These observations highlight the importance of identifying what fraction of the plant is being eaten. There are many recipes that use only the stems of this vegetable. This table lists the oxalate contents of foods that are widely known to contain high levels of oxalates. The levels of oxalates in broccoli, carrots and parsnip are included in this list to show that the levels are low in these vegetables and do not pose a risk even for a person seeking to significantly reduce their oxalate intake. The data in this table clearly show that cooking (boiling in water, the usual way to cook these foods) leads to a significant reduction in the oxalate content of the food eaten.

Table 3. Mean total and soluble oxalate content of some raw and cooked Thai vegetables (mg/100 g FW) (Judprasong et al., 2006)

\begin{tabular}{|c|c|c|c|c|c|}
\hline \multirow[t]{2}{*}{ Thai vegetables } & \multicolumn{2}{|c|}{ Raw foods } & \multicolumn{2}{|c|}{ Cooked foods } & \multirow{2}{*}{$\begin{array}{l}\text { Loss of soluble oxalate } \\
\text { following cooking }\end{array}$} \\
\hline & Total & Soluble & Total & Soluble & \\
\hline Acacia pennata & 703 & 484 & 407 & 226 & 47 \\
\hline Chinese convolvulus & 496 & 69 & 343 & 16 & 23 \\
\hline Ivey gourd & 166 & 48 & 96 & 20 & 42 \\
\hline Swamp morning glory - red stems & 651 & 427 & 406 & 165 & 39 \\
\hline Swamp morning glory - white stems & 454 & 321 & 308 & 220 & 69 \\
\hline Eggplant/brinjal & 699 & 350 & 468 & 179 & 51 \\
\hline Eggplant/aubergine & 408 & 331 & 275 & 135 & 41 \\
\hline Bitter gourd & 486 & 394 & 367 & 143 & 36 \\
\hline Bamboo shoots & 1375 & 1014 & 518 & 278 & 27 \\
\hline Bamboo shoots pickled & 561 & 183 & 409 & 81 & 44 \\
\hline Carrot & 237 & 196 & 85 & 49 & 35 \\
\hline \multicolumn{5}{|c|}{ Mean loss of soluble oxalate following cooking } & $41 \%$ \\
\hline
\end{tabular}

\subsection{Vegetable and Fruit Juices}

The preparation of juice from mixtures of fruits and vegetables is a recent nutritional trend. It is commonly believed that this is a very positive way to consume mixtures of fruits and vegetables. The internet is full of the health benefits juicing can promote - encouraging weight loss and flushing toxins from the body - even though there is no strong scientific evidence to support these claims. It is important to note that the vegetables and fruits, 
and the juices produced from them, are not heated or cooked during preparation and this is seen as an effective way to preserve the beneficial nutrients in the juices. However, this minimal processing does not allow for the reduction of potentially toxic anti-nutrients, such as oxalates, in these juices. Green juices often contain spinach, which is known to contain high levels of oxalates (Brogren \& Savage, 2003; Vanhanen \& Savage, 2015). To some extent, the oxalate contents of green juices containing spinach are moderated by the other plant materials added to the mixture. It is also interesting to note that the preparation of many juices use masticating juicers, which remove a large portion of the fibre fraction from the juices. Vanhanen \& Savage (2015) noted that the discarded fibre fraction contained both soluble and insoluble oxalates and this reduced the oxalate content of the remaining juice. Typical green juices may contain 40\% spinach leaves and the juice will contain $364.2 \mathrm{mg}$ soluble oxalate/100 g of juice. A standard glass contains $200 \mathrm{~mL}$ and reports of people consuming six glasses/day would result in the consumption of $4.4 \mathrm{~g}$ of soluble oxalate/day. There are informal reports of people consuming these sorts of drinks for several days or even weeks. This would result in a very significant intake of soluble oxalates. So far, there are no reports in the scientific literature of severe problems from following these dietary regimes.

In contrast, there have been many problems following the excessive consumption of star fruit juice (Tse et al., 2003). Starfruit, carambola (Averrhoa carambola) is a tasty fruit that contains high levels of soluble oxalates (301.1 mg/100 g fresh weight) (Nguyen \& Savage, 2013). In a period between July 2001 and May 2013 eight out of 20 patients died in two Hong Kong hospitals following regular consumption of star fruit juices. The patients were brought into hospital with a range of acute kidney and kidney stone problems. Indian gooseberry (Phyllanthus emblica) has also been promoted as a new juice. This is unwise, as the fruits have been shown to contain $3.9 \mathrm{~g}$ soluble oxalate/100 $\mathrm{g}$ fresh weight. So far, there have been no reports of problems from regular consumption of this tasty but rather acid fruit or juice made from the fruit.

Bong et al., (2017) showed that the soluble oxalate contents of green juices containing spinach leaves can be significantly reduced by adding very small amounts of calcium-containing salts. For example, they prepared a green juice using $100 \mathrm{~g}$ spinach leaves with $100 \mathrm{~mL}$ tap water. The juice contained $648.2 \mathrm{mg}$ soluble oxalate/100 $\mathrm{g}$ juice. Addition of small amounts of calcium salts (all permitted food additives) significantly reduced the soluble oxalate content in the prepared juice. The soluble calcium salts combined with the soluble oxalate in the juice to form insoluble oxalates, which are not absorbed in the digestive tract. The addition of $300 \mathrm{mg}$ calcium chloride to $100 \mathrm{~g} / \mathrm{green}$ juice reduced the soluble oxalate content by $96 \%$. Addition of small amounts of four different calcium salts had no effect on the colour of the juice and only very small effects on the final $\mathrm{pH}$. These additions could easily be added during the commercial production of both green vegetable juices and coloured fruit juices, but the manufacturers of these juices must recognise and understand the issue of oxalates in some fruits and vegetables. Many manufacturers would have some problems admitting that their products may contain some toxins.

Table 4. Mean oxalate content of some selected fresh Thai vegetables (mg oxalate/100 g FW) (Juajun et al., 2012)

\begin{tabular}{lllll}
\hline English name & Thai name & Total oxalate & Soluble oxalate & Insoluble oxalate \\
\hline Knotweed & Pahk-praew & $1147.3 \pm 11.7$ & $404.3 \pm 2.9$ & $743.0 \pm 9.2$ \\
Variegatum & Chaplu & $1707.5 \pm 18.7$ & $523.0 \pm 15.9$ & $1184.5 \pm 10.2$ \\
Rice paddy plant & Phak kha-yaeng & $778.6 \pm 3.0$ & $44.4 \pm 2.0$ & $734.2 \pm 4.6$ \\
Water mimosa & Krachetnam & $288.5 \pm 7.1$ & $275.7 \pm 0.6$ & $12.8 \pm 6.7$ \\
Lobelia & Pahk-luempua & $49.6 \pm 0.6$ & $8.9 \pm 0.3$ & $40.7 \pm 0.3$ \\
Vegetable humming bird & Khae & $272.2 \pm 13.4$ & $192.6 \pm 4.3$ & $79.6 \pm 9.4$ \\
Bitter gourd & Marakinok & $156.9 \pm 5.3$ & $24.2 \pm 0.9$ & $108.8 \pm 3.2$ \\
Water morning glory & Pahk bungthai & $63.4 \pm 1.2$ & $63.3 \pm 0.8$ & $0.1 \pm 2.1$ \\
\hline
\end{tabular}

\subsection{New foods}

The internet is full of new 'wonder' foods. Some of them are plant foods that were widely used many years ago. More recently, interest has been increased by the suggestion that they many contain high levels of antioxidants, but potential toxins have not been considered so far. There was always the possibility that the plants have been ignored over the years because they were not very tasty or that they had a bitter taste or, even, or that they contain some toxins. Research at Lincoln University is in progress the measure the oxalate content of red orach (Atriplex hortensis), strawberry spinach (Blitum capitatum) and amaranth leaves (Amaranthus tricolor). All these plants are highly coloured and, therefore, may contain high levels of antioxidants, but recent data suggests that 
they also contain high levels of oxalates. Before they are promoted as the latest wonder food the levels of potential toxins such as oxalates should be fully investigated.

\section{Conclusions}

All plant foods contain some oxalates and low levels in many foods are unimportant. Foods that contain high levels of oxalates should be consumed in moderation and, if possible, cooked in a way that reduces the levels of oxalates in the cooked food. Cooking foods in water to leach out soluble oxalates, is one achievable way to reduce the problem but also leads to a loss of nutrients. Cooking foods with added calcium or the addition of foods containing soluble calcium are realistic ways to reduce the input of oxalate into the body. Cooking foods in a wok needs to be considered carefully as the process may allow the binding of soluble oxalate during cooking but, overall, the reduction of the moisture content will tend to concentrate the oxalates in the final cooked food. Considerable care should, therefore, be taken when new 'wonder' plant foods are being promoted for health. Are they related to foods that are already known to contain high oxalates? Is there any data on the oxalate and other toxins present? Green and coloured vegetables and fruits, especially if they contain unfamiliar fruits, should be carefully considered before use, particularly if the composition of the juice is not specified. A green juice is very likely to contain spinach as it is a very cheap leafy plant with a strong, green colour that is easy to process. Fruit juices should be carefully examined, and more analysis made available. Overall, the occasional consumption of high oxalate foods as part of a mixed diet will not pose any health problems. Problems are more likely to occur with people who have diets that contain little variety, especially diets focussed on particular fruits and vegetables or their juices, which are often promoted for their supposed health benefits.

Author Contributions G.P.S. and W. K. drafted the manuscript and critically revised the article for important intellectual content and approved the final manuscript.

\section{Conflicts of Interest}

This work was supported by the Post Graduate Research Fund, Lincoln University. The authors declare no conflict of interest.

\section{References}

Ahmad, S., Ansari, T. M., \& Shad, M. A. (2016). Prevalence of renal calculi, type, age and gender specific in Southern Punjab. Professional Medical Journal, 23(4), 389-395. https://doi.org/10.17957/TPMJ/16.289

Brogren, M., \& Savage, G. P. (2003). Bioavailability of soluble oxalate from spinach eaten with and without milk products. Asia Pacific Journal of Clinical Nutrition, 12(2), 219-224.

Chai, W., \& Liebman, M. (2005). Oxalate content of legumes, nuts and grain based flour. Journal of Food Composition and Analysis, 18(7), 723-729. https://doi.org/10.1016/j.jfca.2004.07.001

Charrier, M. J. S., Savage, G. P., \& Vanhanen, L. (2002). Oxalate content and calcium binding capacity of tea and herbal teas. Asia Pacific Journal of Clinical Nutrition, 11(4), 298-301.

Harvard Health Publications (2017). 5 steps for preventing kidney stones. https://www.health.harvard.edu.

Hodgkinson, A. (1977). Oxalic acid in biology and medicine. Academic Press, New York, USA.

Juajin, O., Vanhanen, L. Sangketkit, C., \& Savage, G. (2012). Effect of cooking on the oxalate content of selected Thai vegetables. Food and Nutrition Sciences, 3, 1631-1635.

https://doi.org/10.4236/fns.2012.312213

Judprasong, K., Charoenkiatkul, S., Sungpuag, P., Vasanachitt, K., \& Nakjamanong, Y. (2006). Total and soluble oxalate contents in Thai vegetables, cereal grains and legume seeds and their changes after cooking. Journal of Food Composition and Analysis, 19, 340-347. https://doi.org/10.1016/j.jfca.2005.04.002

Massey, L. K. (2003). Dietary influences on urinary oxalate and risk of kidney stones. Frontiers in Bioscience, 8 , s584-594.

Mayo Clinic. nd. Kidney stones - Prevention. https://www.mayoclinic.org.

National Institute of Diabetes and Digestive and Kidney Diseases. (2016). Eating, Diet, \& Nutrition for Kidney Stones. https://www.niddk.nih.gov.

National Kidney Foundation. (2014). Diet and kidney stones https://www.kidney.org/atoz/content/diet

Nguyen, H. V. H., \& Savage, G. P. (2013). Total, soluble and insoluble oxalate content of ripen green and golden kiwifruits. Foods, 2(1), 76-82. https://doi.org/10.3390/foods2010076

Nguyen, H. V. H., Hùng, M. L., \& Savage, G. P. (2018). Effects of maturity at harvesting and primary processing 
of cocoa beans on oxalate contents of cocoa powder. Journal of Food Composition and Analysis, 67, 86-90. https://doi.org/10.1016/j.jfca.2018.01.007

Noonan, S. C., \& Savage, G. P. (1999). Oxalate content of food and its effect on humans. Asia Pacific Journal of Clinical Nutrition, 8(1), 64-74. https://doi.org/10.1016/j.jfca.2018.01.007

Radek, M., \& Savage G. P. (2008). Oxalates in some Indian green leafy vegetables. International Journal of Food Sciences and Nutrition, 59(3), 246-260. https://doi.org/10.1080/09637480701791176

Ritter, M. M. C., \& Savage, G. P. (2007). Soluble and insoluble oxalate of nuts. Journal of Food Composition and Analysis, 20, 169-174. https://doi.org/10.1016/j.jfca.2006.12.001

Ruan, Q. Y., Zheng, X. Q., Chen, B. L., Xiao, Y., Peng X. X., Leung, D. W. M., \& Liu, E. (2013), Determination of total oxalate content of a great variety of foods commonly available in Southern China using an oxalate oxidase prepared from wheat bran. Journal of Food Composition and Analysis, 32(1), 6-11. https://doi.org/10.1016/j.jfca.2013.08.002

Savage, G. P., Vanhanen, L. S., Mason, S. M., \& Ross. A. B. (2000). Effect of cooking on the soluble and insoluble oxalate content of some New Zealand foods. Journal of Food Composition and Analysis, 13, 201-206. https://doi.org/10.1006/jfca.2000.0879

Scales, Jr. C. D., Smith, A., Hanley, J., \& Saiga, C. (2012). Prevalence of kidney stones in the United States. European Urology, 62(1), 160-165. https://doi.org/10.1016/j.eururo.2012.03.052

Taylor, E. N., \& Curhan, G. C. (2008). Determination of 24-hour urinary oxalate excretion. Clinical Journal of the American Society of Nephrology, 3(5), 1453-1460. https://doi.org/10.2215/CJN.01410308

Tse, K. C., Yip, P. S., Lam, M. F., Choy, B. Y., Li, F. K., Lui, S. L., Lo, W. K., Chan, T. M., \& Lai, K. N. (2013). Star fruit intoxication in uraemic patients: case series and review of the literature. Internal Medical Journal, 33(7), 314-316. https://doi.org/10.1046/j.1445-5994.2003.00402

USDA (1984). Vegetables and Vegetables Products. Agriculture Handbook No. 8-11. https://naldc.nal.usda.gov

USDA (2016). Agricultural Research Service. National Nutrient Database for Standard Reference. https://ndb.nal.usda.gov.

Vanhanen, L., \& Savage, G. P. (2015). Comparison of oxalate contents and recovery from two green juices prepared using a masticating juicer or a high speed blender. NFS Journal, 1, 20-23. https://doi.org/10.1016/j.nfs.2015.07.002

Bong, W-C., Vanhanen, L. P., \& Savage, G. P. (2017). Addition of calcium compounds to reduce oxalate in a high oxalate food system. Food Chemistry, 221, 54-57. https://doi.org/10.1016/j.foodchem.2016.10.031

\section{Copyrights}

Copyright for this article is retained by the author(s), with first publication rights granted to the journal.

This is an open-access article distributed under the terms and conditions of the Creative Commons Attribution license (http://creativecommons.org/licenses/by/4.0/). 